Article

\title{
Environmental Regulations and $\mathrm{CO}_{2}$ Mitigation for Sustainability: Panel Data Analysis (PMG, CCEMG) for BRICS Nations
}

\author{
Muddassar Sarfraz $^{1}$ (D), Larisa Ivascu ${ }^{2}$ and Lucian-Ionel Cioca ${ }^{3, *(D)}$ \\ 1 College of International Students, Wuxi University, Wuxi 214105, China; muddassar.sarfraz@gmail.com \\ 2 Management Department, Faculty of Management in Production and Transportation, Politehnica University \\ of Timisoara, 300191 Timisoara, Romania; larisa.ivascu@upt.ro \\ 3 Department of Industrial Engineering and Management, Faculty of Engineering, \\ Lucian Blaga University of Sibiu, 550024 Sibiu, Romania \\ * Correspondence: lucian.cioca@ulbsibiu.ro
}

Citation: Sarfraz, M.; Ivascu, L.; Cioca, L.-I. Environmental Regulations and $\mathrm{CO}_{2}$ Mitigation for Sustainability: Panel Data Analysis (PMG, CCEMG) for BRICS Nations Sustainability 2022, 14, 72. https:// doi.org/10.3390/su14010072

Academic Editors: Aykan Karademir and Diana Mariana Cocârtă

Received: 1 December 2021

Accepted: 20 December 2021

Published: 22 December 2021

Publisher's Note: MDPI stays neutral with regard to jurisdictional claims in published maps and institutional affiliations.

Copyright: (C) 2021 by the authors. Licensee MDPI, Basel, Switzerland. This article is an open access article distributed under the terms and conditions of the Creative Commons Attribution (CC BY) license (https:// creativecommons.org/licenses/by/ $4.0 /)$.

\begin{abstract}
The relationship between income and pollution is contested, yet wealth alone is insufficient to regulate emissions, which necessitates environmental regulations. Even if inadequate environmental laws may overcome market failures produced by pollution's negative externality, a thorough examination of their function in pollution management is critical. This research takes a step forward in offering a fresh viewpoint on the function of environmental laws in pollution reduction for BRICS (Brazil, Russia, India, China, and South Africa) nations to better understand the role of environmental regulations in $\mathrm{CO}_{2}$ emission mitigation. The research presented here uses panel data econometric methodologies to achieve this goal, using data from 1995 to 2018. In addition, to provide country-specific findings, the research employs a completely modified ordinary least squares estimator. Environmental laws provide a beneficial influence in reducing carbon emissions. According to the empirical findings, the present environmental regulation positively meets pollution reduction objectives in chosen nations. The environment Kuznets curve (EKC) between pollution and income is controlled by environmental restrictions. Climate change mitigation in BRICS nations is driven by strong environmental policies and economic growth.
\end{abstract}

Keywords: BRICS; $\mathrm{CO}_{2}$ emissions; environmental regulations; international trade; $\mathrm{CO}_{2}$ mitigation; CCEMG; PMG-ARDL; CPIS unit root test

\section{Introduction}

The profound historical reputation of emerging air pollutants has driven human civilization to experience the adverse consequences of global climate. In recent years, abrupt atmospheric changes have impacted the global economies while having a devastating effect on human settlements. The accelerating environment depletion has been triggered by human activities, causing climate change to depreciate the environmental quality. In particular, atmospheric degradation due to the emission of abundant air waste has challenged countries globally. These environmental impurities include the secretion of harmful intoxicants such as smoke, dust, and gases. Among them, greenhouse emissions play a critical role in regressing air quality. The increasing concentration effect of air pollutants has lessened the atmospheric quality, thereby making environmental sustainability a vital concern of meteorologists. In the current scenario, global climate change has made economists and environmentalists consider the colossal emission of carbon dioxide as the prime cause of atmospheric degradation [1]. The growing environmental concerns are directly related to carbon dioxide emitted into the atmosphere, and it is known that fossil energy consumption is a significant contributor to this situation [2]. $\mathrm{CO}_{2}$ concentrations have climbed to their greatest level in several decades and have been a key component of greenhouse gas emissions, accounting for more than $55 \%$ of total emissions [3]. Thus, 
$\mathrm{CO}_{2}$ emissions are a primary cause of climate change and global warming [4]. Parallel to the increase in $\mathrm{CO}_{2}$ emissions, the fastest-growing hazard to civilization has been climate change. BRICS (Brazil, Russia, India, China, and South Africa) countries have witnessed unprecedented economic development for the last 20 years. The BRICS countries account for $45 \%$ of the world's population, contributing almost $23 \%$ to the world's gross domestic product, absorbing $38 \%$ of global energy and accounting for a sizable portion of global $\mathrm{CO}_{2}$ emissions. Fast economic expansion in BRICS nations has exacerbated the burden on the environment [5]. Greenhouse Gas Emission (GHG) reduction is critical for mitigating the worst effects of climate change and is tied to the degree of commitment of $\mathrm{CO}_{2}$-emitting countries to addressing the problem [6]. BRICS nations are attempting to pursue and embrace pollution-reduction measures, and technology advancement is widely acknowledged as the main driver in decreasing $\mathrm{CO}_{2}$ emissions. Meanwhile, $\mathrm{CO}_{2}$ emissions are unintended outcomes of manufacturing and consuming processes, necessitating additional controls such as environmental legislation [7].

It is not only government and academic publications that pay attention to environmental degradation. The current century will be witness to a great threat to human health, as global warming and climate change abrogate and devastate our planet's ecosystems [4]. The international community's primary concern has been to increase economic prosperity while preserving environmental quality [8]. As a result, it has been established that economic expansion alone may not be enough to combat environmental deterioration, and environmental restrictions should accompany it. A "green paradox" will result when resource owners are encouraged to boost extraction levels by a stringent carbon tax or slack policy enforcement [9]. Due to the lax policies implemented by emerging nations, international corporations are encouraged to invest in non-eco-friendly industries and move non-eco-friendly technologies to these countries, allowing them to gain reasonable advantages in producing non-eco-friendly products.

Economic prosperity needs to be matched with the deployment of environmental regulations to minimize the strength of $\mathrm{CO}_{2}$ emissions. Simultaneously, technological advancement allows firms to produce environmentally friendly products, effectively adding to the nations' prosperity. To mitigate the adversity of $\mathrm{CO}_{2}$ emissions, regulatory authorities are rapidly adopting green solutions, thus enhancing nations' capabilities to produce sustainable products. Given this, a study analyzing the BRICS economies recorded a negative relationship between innovation and $\mathrm{CO}_{2}$ emission in Russia, Chania, and India [10]. Indeed, the literature indicates that environmental innovation technologies in China play a dominant role in achieving sustainable economic development, thus restricting $\mathrm{CO}_{2}$ emission [11].

In contrast, foreign direct investment (FDI) can significantly reduce environmental pollution if foreign businesses use environmentally friendly technology in their manufacturing processes [12]. Moreover, governments in developing nations can enforce environmental policy requirements on foreign investors. Governments need to implement adequate legislation to counteract any market failure that causes environmental pollution, in addition to responding to public concern over environmental degradation [13]. The function of environmental regulation in climate change mitigation is still undecided. Consensus on climate change causes is difficult to achieve due to differences in economic structure between countries. As such, climate change-related policy formation can benefit from empirical research.

Indeed, the global atmospheric concerns regarding the increasing greenhouse effect (i.e., carbon dioxide emission) need proper consideration [14]. The objectives mentioned above recommend that sophisticated econometric approaches explore the influence of environmental policies and income levels in reducing $\mathrm{CO}_{2}$ emissions in BRICS nations. This inquiry is urgent and useful given the importance of environmental rules and international commitments to environmental concerns in BRICS nations. Perhaps, this study holds a significant practical value by justifying environmental concerns through ensuring environmental sustainability. This paper demonstrates academic progress and warns about 
the deteriorating effects of carbon dioxide emissions in BRICS nations. This work focuses on sustainable development by encouraging economists, researchers, and meteorologists to study the socio-economic factors contributing to environmental sustainability.

This study aims to explore the environmental practices of BRICS countries in promoting atmospheric sustainability. Environmental development plays a significant role in accelerating nations' economic growth, thus improving human wellbeing. Today, the world has reached a new era where atmospheric sustainability has become essential for achieving economic growth. As a result, most countries engage in relevant mitigation activities, thus ensuring sustainable development. Significantly, this paper helps to understand the new scenarios of environmental sustainability in BRICS countries, supporting the need to address the climatic problems linked with sustainable development.

Furthermore, this paper outlines the effects of environmental regulations on income and pollution. Income cannot overcome pollution alone; however, environmental regulations along with income can overcome pollution. Our study aims to verify that environmental regulations and income can overcome carbon emissions and help to mitigate pollution. Variables such as energy consumption, international trade, foreign direct investment, and gross domestic product are used for verification. The next section provides a literature review of environmental regulations in BRICS nations; Section 3 provides the methodology; Section 4 outlines the study's results; Section 5 offers conclusions.

\section{Study Background}

Undoubtedly, sudden climate change poses an immense risk to humanity today. Changes in the global environmental have brought numerous challenges leading to massive ecological disasters. Carbon dioxide emissions have a devastating effect on nations ${ }^{\prime}$ economic sustainability. In particular, the growing atmospheric vulnerability needs to be controlled, thus generating enduring results. Therefore, the world's governments have started adopting environmental regulation policies to lower carbon emissions. Governments have pursued green development strategies to ensure environmental sustainability. Indeed, these climate-friendly practices facilitate nations' development, thus forming carbon-free regions.

Environmental problems have gained prominence in recent years. Sustainable environmental regulations effectively achieve environmental welfare [15]. In particular, diversified human activities and increasing environmental degradation have compelled economies worldwide to compromise on their country's economic growth. Heightened concerns about the climate have encouraged nations to adopt innovative environmental policies to attempt to secure the global environment. In recent years, the increasing effectiveness of atmospheric regulations has minimized the negative effect of air pollutants. Nathaniel [16] indicate that nations adopting environmental regulations have gained tremendous sustainable economic growth, subsequently reducing $\mathrm{CO}_{2}$ emissions.

Consequently, to achieve an eco-environment, the prime source of environmental degradation (i.e., fossil fuel) needs to be shifted to clean renewable energy. The increased utilization of renewable energy resources reduces environmental pollution, thus contributing to sustainable development. Consistently, to promote atmospheric sustainability, governments are taking necessary steps to mitigate the negative consequences of carbon dioxide emissions. In support, the research shows that governments are embracing energy-saving strategies, thus restricting the emission of carbon dioxide [17].

Earlier research on the link between environmental regulations and carbon emissions is limited and inconsistent. For instance, one researcher used the generalized method of moments generalized method of moments (GMM) methodology to analyze the efficiency of environmental legislation in 279 Chinese cities from 2003 to 2010. The study concluded that environmental measures are ineffective in reducing pollution [18]. Another researcher used dynamic spatial models to examine the influence of many environmental laws and regulations on $\mathrm{CO}_{2}$ emissions. The study concluded that regulatory rules benefit $\mathrm{CO}_{2}$ emission reduction [19]. Notably, the Chinese government has introduced $\mathrm{CO}_{2}$ reduction 
schemes to achieve sustainability goals. To do so, China has formulated greenhouse control plans, lowering carbon dioxide intensity. The research supports the notion that China's renewable energy policies have successfully reduced carbon development, thus achieving the sustainability objective [20].

The growing global concerns about climate change have made carbon footprint mitigation a critical topic for acquiring environmental sustainability. In particular, efforts have been made by the world's governments to minimize the effect of the changing climatic conditions. As a result, most countries have emphasized reducing greenhouse emissions (i.e., $\mathrm{CO}_{2}$ ) to ensure a safe and secure sustainable future. In recent years, assuring sustainable development through the introduction of green technologies has been given considerable importance by economists. Green technology has strengthened the economic activities of many nations. In the context of sustainable development practices, this novel mechanism (i.e., green technology) has reduced the environmental impact of air pollution, thus opening new markets for sustainable products. Indeed, the research shows that green technological innovation develops environmentally friendly products, thereby allowing energy efficiency to foster nations' economic growth [21,22].

Consistently, the GMM estimator has been used to conduct empirical research in China to examine the link between corruption and environmental regulations in 30 provinces. Their empirical findings indicate that more stringent environmental control would reduce pollution [23]. Researchers from China examined the mediating effect of technological efficiency in the relationship between environmental legislation and $\mathrm{CO}_{2}$ emissions in China using provincial data from 2005-2015. The empirical findings indicate that environmental restrictions directly reduce $\mathrm{CO}_{2}$ emissions, whereas technological efficiency indirectly affects it [24]. In 2019, the Granger causality technique was used to estimate the effect of economic policy uncertainty on carbon emissions using US sectoral data. The findings demonstrate that economic policy uncertainty affects $\mathrm{CO}_{2}$ emissions across all industries [25]. The GMM approach was used in 2019 to examine the dynamic impact of innovation and environmental regulation on Organisation for Economic Co-operation and Developmen (OECD) nations from 1999 to 2014. The study's findings validate the beneficial function of environmental legislation in pollution reduction [26].

Additionally, with increasing innovative activities, the demand for fiscal development also affects environmental conditions. By rigorously adopting monetary policies, governments and policymakers disrupt the emission of $\mathrm{CO}_{2}$, thus enhancing the relationship between green innovation and FDI. Generally, entrepreneurs use traditional technologies in the production process due to the increased interest rates, thus leading to higher emissions of $\mathrm{CO}_{2}$. Given this, the research stated that the ecological footprint of production disrupts greenhouse emissions in the long run [27]. In particular, FDI is necessary for reducing the negative effect of conventional technologies on the environment. To acquire a clean environment, it is necessary to look deeply into the context of FDI for maintaining environmental quality [28,29].

Significantly, governments should not ignore the role of FDI in achieving sustainable economic development objectives. Another researcher employed threshold analysis to investigate the relationship between economic development, environmental regulations, and air pollution in 30 OECD nations, focusing on socioeconomic determinants. They used PM2.5 as a proxy for pollution. The study's findings demonstrate the heterogeneous effect of regulations on air pollution [30]. In 2019, the link between environmental legislation, renewable energy, and $\mathrm{CO}_{2}$ emissions in the European Union (EU) member states from 1990 to 2017 was noted. According to dynamic and GMM analyses in the study, the function of environmental legislation in mitigating $\mathrm{CO}_{2}$ emissions is uncertain [31,32].

The link between environmental regulation and environmental pollution in China was researched in 2019 using a variety of pollution proxies. The researchers discovered that diverse environmental regulations had varying effects on pollutants [33]. Additionally, several environmental rules regarding China's environmental performance were investigated in 2018. The study authors found that, whereas command and control laws and market- 
based regulations have a non-linear but beneficial effect on environmental performance, the function of informal regulations is unknown [34]. The pollution halo hypothesis's consistency in China, using a new metric of environmental control, was investigated in 2018. The findings are startling, suggesting that diverse measurements have a varied influence on the pollution hypothesis [35]. Further, Bayesian posterior probability was used to assess the influence of environmental policies in lowering pollution in 30 Chinese provinces from 2003 to 2016. Environmental rules, the study discovered, have a considerable spillover impact and are beneficial for reducing environmental pollution in China. However, environmental rules exacerbate pollution related to industrial accumulation [36,37]. In 2021, researchers proposed that greening policy can reduce $\mathrm{CO}_{2}$ emissions immediately, and the DAE model was used to analyze greening policy and its effects on the environment [38]. In 2021, Wang stated that China's green development was successful during the time period of 2010 to 2012. After that, China has not succeeded to overcome the U-shape of EKC. Wang used the spatial econometric method to analyze the results [39].

Researchers continue to debate the link between environmental laws and $\mathrm{CO}_{2}$ emissions; however, the mechanism by which environmental rules affect carbon emissions remains murky. It is rare for researchers to examine how environmental rules could affect carbon emissions and whether or not they do so. The results of previous studies focusing on these interconnections have been largely inconclusive. The BRICS nations have also been spared from such an examination. Consideration of the relationship between environmental regulations and carbon emissions via international commerce is now needed because of a lack of inquiry into the underlying factors, ambiguous conclusions, methodological issues, and lack of data in specific groupings of nations. Many studies have explored how $\mathrm{CO}_{2}$ emissions are affected by environmental regulations in China, most likely because China is one of the BRICS nations that contributes most to global $\mathrm{CO}_{2}$ emissions. However, the findings show that further research is needed to fully understand the effect of environmental regulations on reducing emissions. One can see that the BRICS nations, which use $45 \%$ of the world's energy and produce a significant portion of its carbon emissions, have not been researched extensively. This study focuses on how environmental policies in BRICS nations effectively reduce emissions by employing second generation panel data methodologies that consider cross-sectional dependency. Figure 1 shows $\mathrm{CO}_{2}$ mitigation and environmental regulations.
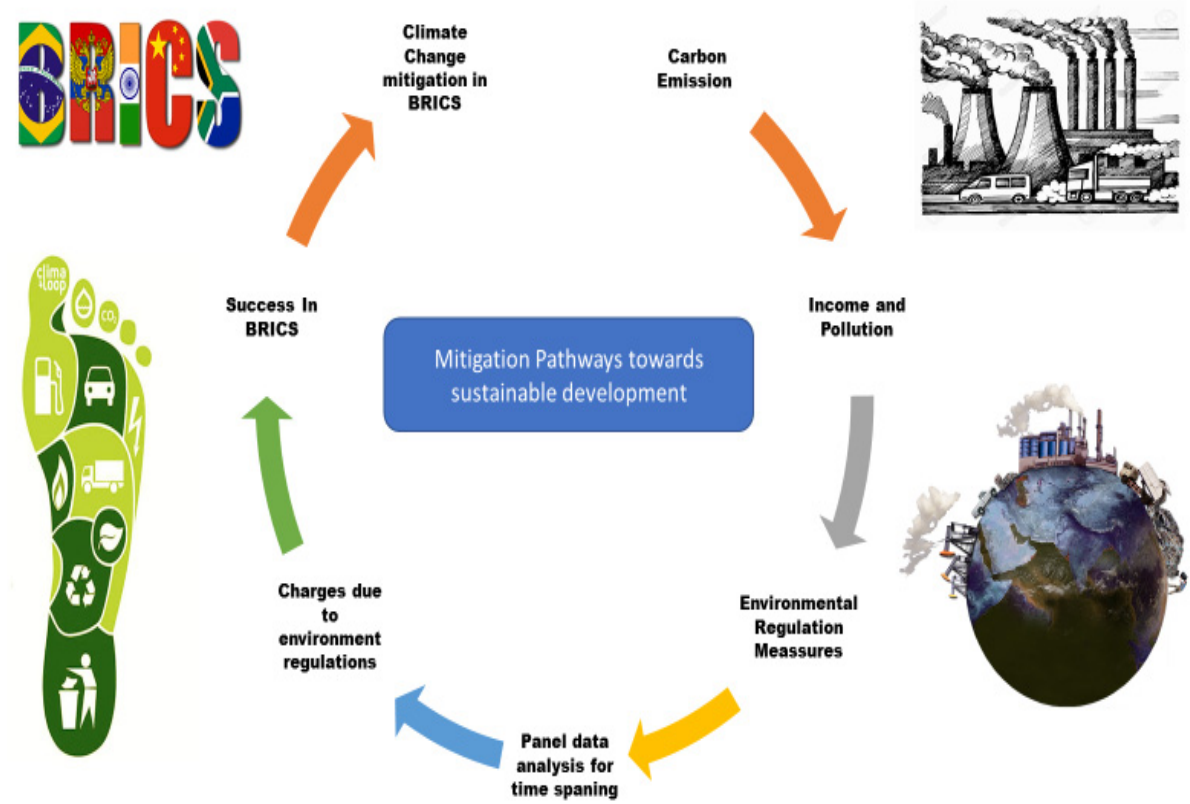

Figure 1. $\mathrm{CO}_{2}$ Mitigation and Environmental Regulations. 


\section{Methods}

\subsection{Data}

From 1995 to 2018, time-series data for BRICS nations was evaluated. $\mathrm{CO}_{2}$ emissions are considered a major variable, whereas environmental regulations and income are considered descriptive factors. Apart from that, international trade and energy consumption are control variables. Carbon emissions are expressed in million metric tons of oil equivalents of carbon emissions per capita. Income is expressed in variable terms as GDP per capita (constant 2015 US dollars). Energy consumption is the amount of energy used before it is converted to another form of energy. The energy consumption of each person is expressed in kilos of oil equivalent. Gross domestic product (GDP) per capita and the energy consumption are derived from the World Bank's development indicators (WDI) collection. Aggregating imports and exports calculate international commerce as a percentage of gross domestic product. Environmental regulation is the study's primary focus and primary explanatory variable. Due to generally poor data quality, it is difficult to extract useful data for assessing environmental control. Environmental rules are divided into two categories on the Organization for Economic Co-operation and Development's website: environmental taxation and patents on environmental technology. Due to the lack of environmental tax data for the research's sample nations, this study currently relies on patents for environmental technology as a proxy for environmental legislation. Patent data possess several desirable characteristics compared to other alternative measures of innovation. They are readily accessible, quantifiable, comparable, and output-based. The OECD website contains information on international trade and environmental control.

\subsection{Model Specifications}

Environmental regulation can directly or indirectly affect the environment via the demand effect. Negative environmental regulations may directly impact governments, businesses, and homes' willingness to reduce $\mathrm{CO}_{2}$ emissions.

As a result, both businesses and households will fail to comply with key environmental regulations to reduce $\mathrm{CO}_{2}$ emissions, increasing carbon emissions. Indirectly, environmental policies may stimulate economic activity such as investment, trade, and the stock market, hence increasing energy consumption. For slower economic development, governments may implement measures to boost economic growth, resulting in environmental policy uncertainty; due to neglect, $\mathrm{CO}_{2}$ emissions might increase during such a time period [25]. Uncertainty about environmental policy or lax environmental laws encourages carbon-intensive firms in foreign direct investment to move from industrialized nations to emerging nations with less severe environmental rules [40]. On the other hand, when economic expansion accelerates, environmental laws can mitigate any market failure that results in a rise in pollution and respond to public concern about environmental quality [24]. Environmental restrictions limiting overall energy usage and promoting energy efficiency are important for pollution management [31]. Apart from being a critical instrument for pollution management, environmental regulations are viewed as critical in countries crossing the EKC barrier and achieving a win-win outcome in terms of $\mathrm{CO}_{2}$ emission reductions and economic development [7].

The empirical model used includes international trade, energy consumption, and higher quality measurement of environmental control (patents on environmental technology). The following model form is used for this study:

$$
\mathrm{LnCO}_{2 i t}=\alpha+\beta_{1} \operatorname{Lny}_{i t}+\beta_{2} \operatorname{Ln}\left(y_{i t^{2}}\right)+\beta_{3} \operatorname{LnEC}_{i t}+\beta_{4} \operatorname{LnER}_{i t}+\beta_{5} \operatorname{LnIT}_{i t}+\mu_{i t}
$$

In Equation (1), the log-linear function is required to prevent scaling difficulties and to interpret the estimated coefficients derived in elasticity form [31]. In Equation (1), $\alpha$ denotes the constant term, and $\beta$ denotes the predicted partial slope parameters. Subscripts $t$ and $i$ denote the study's time frame, which is 1995-2018 for five BRICS nations. $\mu_{i}$ is an error term in an estimated model that covers the influence of all unobserved variables. The signs 
of $\beta_{1}$ and $\beta_{2}$ are positive and negative. These signs will have positive or negative effects on carbon dioxide emissions. This is due to the trade-off between pollution and income, referred to as the environmental Kuznets curve hypothesis. According to the environmental Kuznets curve, income affects pollution via scale, composition, and method. Economic growth stimulates industrialization, resulting in a rise in energy usage and wastes that harm the environment [6].

$\beta_{3}$ is projected to have a beneficial effect on energy usage because energy usage, particularly based on fossil fuels, increases $\mathrm{CO}_{2}$ emissions, which are the primary contributors to global greenhouse gasses. However, the research demonstrates unequivocally that energy use is a primary source of carbon emissions. As a result, environmental contamination is disconnected from the trend of energy consumption increase [41]. According to the Intergovernmental Panel on Climate Change's report, energy is the primary source of worldwide anthropogenic greenhouse gas emissions and contributes to economic development. Predicted expansion of an energy-dependent economy leads to increased pollution associated with energy use [42]. The model incorporates energy usage as a result of this.

International trade (IT) is another major indication of environmental contamination that has received much attention in the literature. We use IT as a control variable in Equation (1) to eliminate omitted variable bias. International trade and environmental rules are likewise inextricably linked. Environmental rules may impose safeguards or restrictions on commerce, affecting the economy's composition. Government efficiency may result in increased trade openness due to crucial environmental rules [11].

Energy consumption may decline due to more efficient technology usage, facilitated by IT that promotes the economy's sustainable development through resources efficiency \& scale economies [43]. Additionally, IT plays the main role in spreading renewable energy and sustainable technologies. On the other hand, the scale effect relates to the expansion of IT. Hence, international trade stimulates economic growth through increased production and transportation services and consumption of products, among other things. Thus, IT may degrade the quality of the environment by promoting activity [44]. Additionally, technology transfer via international trade may be energy-demanding yet contribute to pollution [45], with arguments that trade operations might have a dual influence on the environment in mind being a positive or negative indication for $\beta_{5}$.

\subsection{Economic Method}

The time span is adequate to examine cross-correlations across nations and unit root qualities of each variable, according to data from research variables used in Equation (1). Checking cross-country dependencies among the study's variables serve as a reference for selecting further econometric tests, such as unit roots and cointegration tests, for use in the empirical analysis $[46,47]$. A CD test established by Pesaran is used to examine the cross-sectional dependence (CD) among the panel's parts (2004). Later, Westerlund's (2007) cointegration test, which generates trustworthy outcomes under heterogeneity and CD, is used to evaluate the long-run connection among research variables. This work uses a common correlated effects group mean estimator, which is subsequently enhanced and which is consistent with recent findings [48,49]. The choice of the common correlated effects group mean estimator is based on assumptions of cross-country dependencies and data heterogeneity. Aside from that, the common correlated effects group mean estimator in the data corrects for structural breakdowns and nonstationary unobserved common components. It generates panel-level estimation based on the average of individual group estimations. In the instance of our model, the common correlated effects group mean (CCEMG) estimate process is as follows:

$$
\mathrm{CO}_{2 \mathrm{i}, \mathrm{t}}=\alpha+\delta_{\mathrm{i}} \mathrm{X}_{\mathrm{i}, \mathrm{t}}+\mu_{1} \mathrm{CO} \overline{\mathrm{O}}_{2 \mathrm{t}}+\mu_{1} \overline{\mathrm{X}}_{\mathrm{t}}+\mu_{\mathrm{i}, \mathrm{t}}
$$

where $\mathrm{X}$ is a set of explanatory variables in a matrix. As proxies for unobserved variables $\mathrm{CO}_{2}$ and $\overline{\mathrm{X}}$ Cross-section panel averages of dependent and independent variables are utilized [50]. Common correlated effects group mean estimator produces steady estimates, 
permits time-variant unobservable variables with diverse influence among panel members, and is most efficient in the presence of common components. This approach can deal with a finite number of "strong" unobserved common factors as well as an unlimited number of "weak" factors [51]. When the panel variables are nonstationary, CCEMG is proven to be one of the most resilient approaches. Common correlated effects group mean estimator is calculated as follows:

$$
\mathrm{CCEMG}=\mathrm{N}^{-1} \sum_{\mathrm{i}=1}^{\mathrm{N}} \beta \mathrm{i}
$$

\section{Results}

\subsection{Cross-Sectional Dependence and CPIS Unit Root Test}

The empirical portion starts with a study of cross-country, cross-sectional dependencies (CD) test using Psarian's (2004), the findings of which are shown in Table 1. The findings support that no cross-sectional dependency has rejected the null hypothesis and suggests that cross-country dependencies do exist. This indicates that, when a shock happens in one nation, it has a spillover impact on the study's sample countries [48]. Based on CD test findings, the next stage is to investigate the series stationarity level. It is worth noting that those methodologies utilized in each phase of the investigation are resilient to crosssectional dependency to prevent discrepancies. The Second- generation panel unit root test (CIPS) is used to verify cross-country dependencies. The CIPS panel unit root test findings are shown in Table 1. Results for the CPIS test show that variables are non-stationary at level (0) but become stationary at level (1). This means that series data are first order integrated. Figure 2 is the graphical representation of $C D$ test results while Figure 3 shows CPIS test results.

Table 1. Results of CD and CPIS Unit Root Test.

\begin{tabular}{ccccccc}
\hline Test & Ln $\left(\mathrm{CO}_{2}\right)$ & $\operatorname{Ln}(\mathbf{Y})$ & $\operatorname{Ln}(\mathbf{Y} 2)$ & $\operatorname{Ln}(\mathrm{ER})$ & $\operatorname{Ln}(\mathrm{EC})$ & $\operatorname{Ln}(\mathrm{IT})$ \\
\hline CD test & 9.53 & 13.85 & 13.76 & 3.06 & 9.05 & 4.93 \\
\hline CIPS (at level) & -2.672 & -2.293 & -2.375 & -4.241 & -2.773 & -2.128 \\
\hline $\begin{array}{c}\text { CIPS (at 1st } \\
\text { difference) }\end{array}$ & -4.673 & -2.301 & -3.405 & -5.554 & -3.337 & -3.131 \\
\hline
\end{tabular}

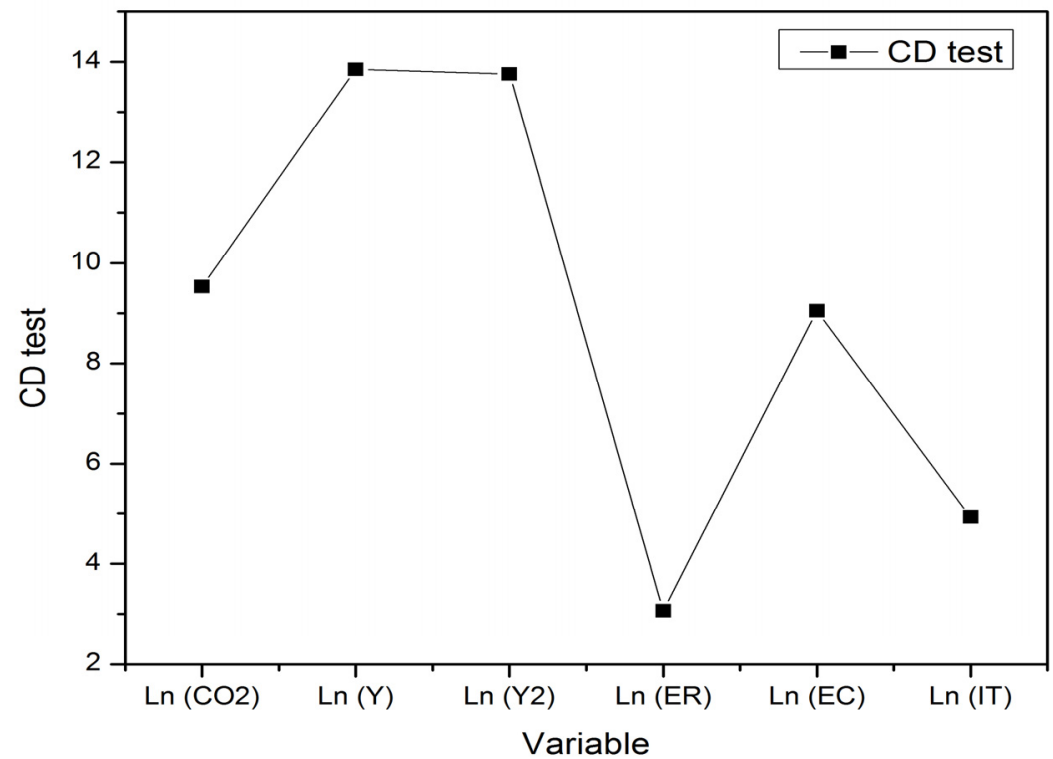

Figure 2. Results of Cross-section Dependence (CD) Test. 


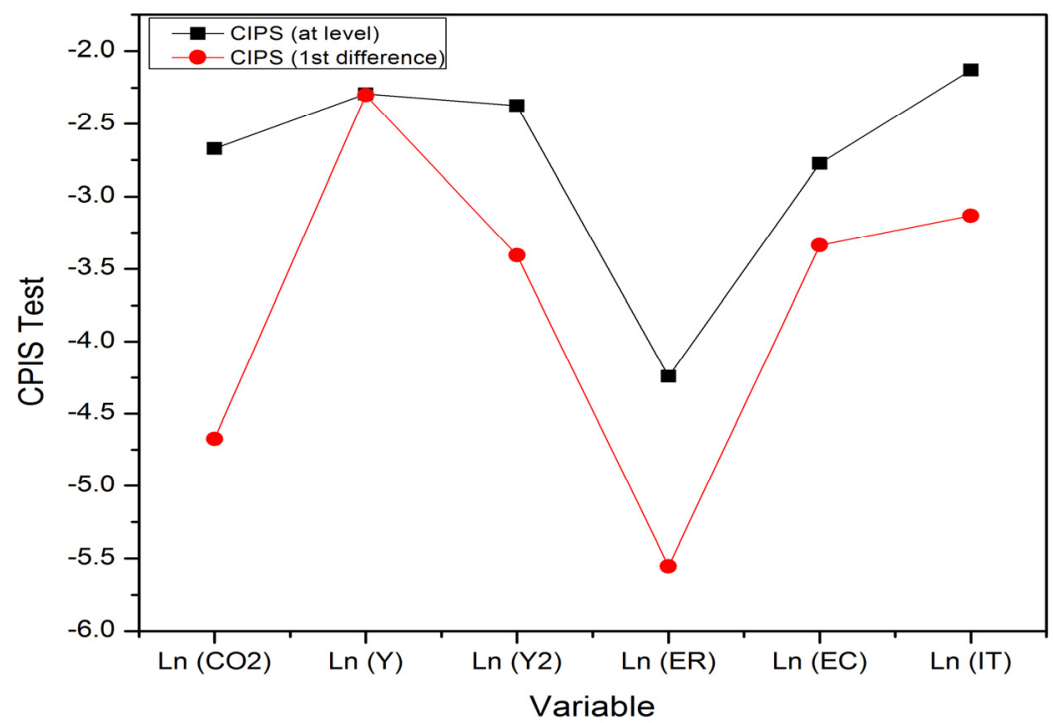

Figure 3. CPIS Test Results.

For data series, the first level of integration necessitates the examination of cointegration relationships between research variables. Westerlund's cointegration test (2007) is used for verification. Results indicate the rejection of the null hypothesis for "no cointegration connection" (see Table 2).

Table 2. Westerlund's Test Results.

\begin{tabular}{ccccc}
\hline Statistic & $\mathbf{G}_{\mathbf{a}}$ & $\mathbf{G}_{\mathbf{t}}$ & $\mathbf{P}_{\mathbf{t}}$ & $\mathbf{P}_{\mathbf{a}}$ \\
\hline Value $(p$-value) & $-8.471[0.820]$ & $-3.951 *[0.000]$ & $-8.732 *[0.000]$ & $-10.109[0.271]$ \\
\hline Note: ${ }^{*}$ shows significance level of $1 \%$. & & &
\end{tabular}

\subsection{CCE-MG Test, GM-FMOLS Test E PMG-ARDL Test}

Once the cointegration connection between the research variables is established, longterm variables are calculated using the Common correlated effects group mean estimator. Additionally, robustness tests are performed using group mean fully modified ordinary least squares and pooled group mean estimators. Table 3 summarizes the findings for all three estimating approaches. Income with variable Ln (Y) and income squared Ln (Y2) are statistically significant and have positive and negative coefficient signs, respectively. The data demonstrate a non-linear association between pollution and income and are consistent with the EKC hypothesis's inverted U-shaped curve.

Table 3. CCE-MG, PMG-ARDL and GM-FMOLS Test Results.

\begin{tabular}{cccc}
\hline Variable & CCE-MG & PMG-ARDL & GM-FMOLS \\
\hline Ln $\left(\mathrm{Y}^{2}\right)$ & $-0.2371^{*}[0.000]$ & $-0.1403 *[0.000]$ & $-0.024{ }^{*}[0.002]$ \\
\hline Ln $(\mathrm{Y})$ & $3.9854^{*}[0.000]$ & $2.3894 *[0.000]$ & $0.4204 *[0.001]$ \\
\hline $\operatorname{Ln}(\mathrm{IT})$ & $0.0502[0.763]$ & $-0.1053[0.738]$ & $0.0395[0.1209]$ \\
\hline $\operatorname{Ln}(\mathrm{ER})$ & $-0.0481^{* * *}[0.052]$ & $-0.1751 *[0.000]$ & $-0.0258 * * 0.025]$ \\
\hline $\operatorname{Ln}(\mathrm{EC})$ & $0.7885^{* *}[0.023]$ & $0.6742 *[0.000]$ & $0.8649 *[0.000]$ \\
\hline
\end{tabular}

Note: ${ }^{*}, *$ and ${ }^{* * *}$ show significance level of $1 \%, 5 \%$ and $10 \%$, respectively.

Additionally, the energy consumption coefficient Ln (EC) has +ve values. Environmental restrictions Ln (ER) have a negative and statistically significant effect. Finally, international trade Ln (IT) is a beneficial and statistically significant environmental effect. As seen in Table 3, Panel Model Estimation autoregressive distributive lag technique (PMGARDL) and group mean fully modified OLS (GM-FMOLS) findings are very compatible 
with the MG-CCE results. Although gross domestic product and energy usage have greater coefficients than environmental regulations in Table 3, their cumulative impact on pollution may outweigh the negative effect of restrictions. According to this, one may argue that environmental rules are less effective in reducing pollution. Figure 4 shows CCE-MG and PMG-ARDL test results while Figure 5 represents MG-FLOMS test results.

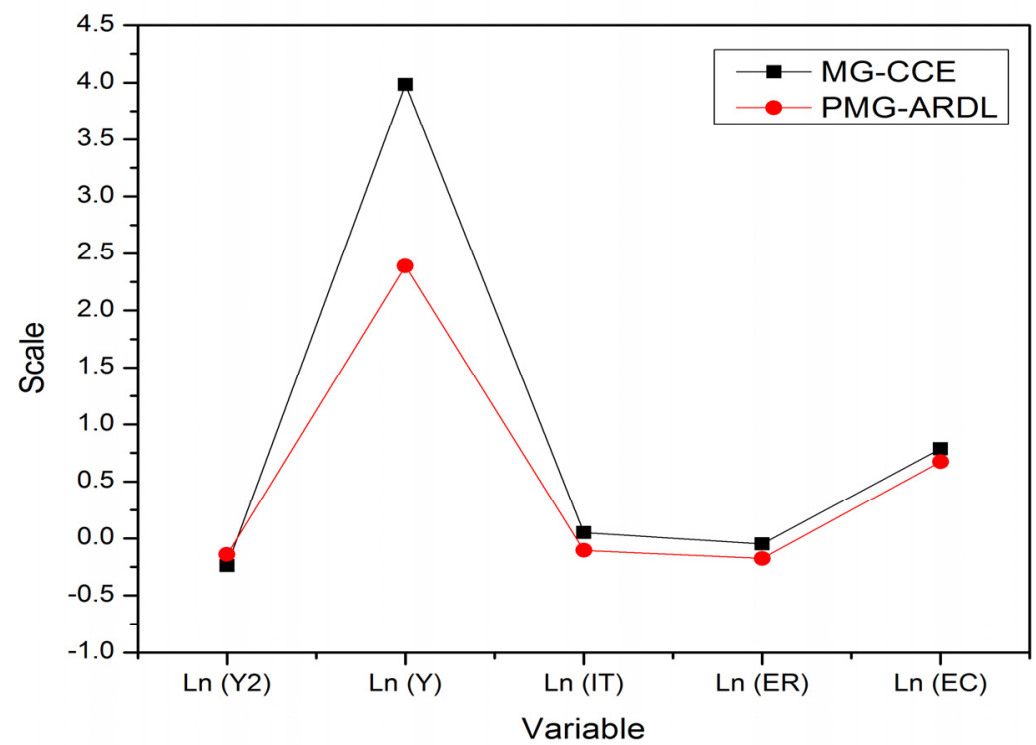

Figure 4. Results of CCEMG and PMG-ARDL Test.

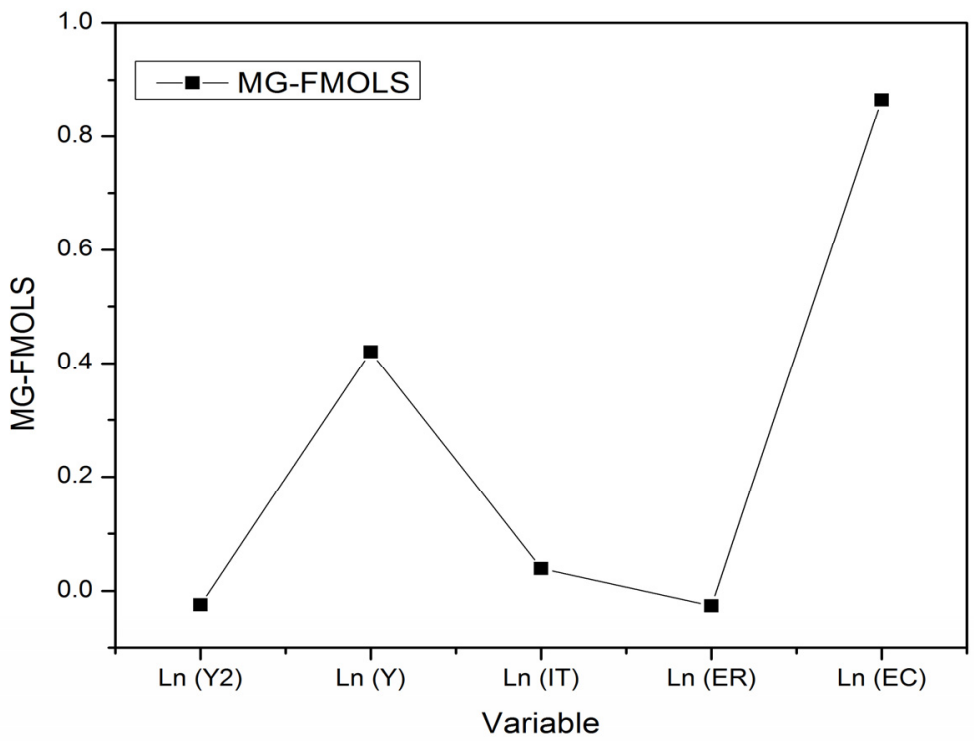

Figure 5. Results of Group-Mean Fully Modified OLS (GM-FMOLS) Test.

To gain more detailed information on selected nations, nation-specific estimates and coefficients are produced using the group mean fully modified ordinary least squares estimator. Findings are summarized in Table 4. Values of Ln (Y) and Ln (Y2) are positive and negative, respectively, confirming the BRICS nation's EKC relationship between pollution and per capita income. However, environmental regulations have a negative and statistically significant effect on all nations. However, the reaction of nations to $\mathrm{CO}_{2}$ emissions for international trade varies, and trade has a positive correlation with pollution in Brazil and India but a negative correlation with pollution in South Africa. In contrast, the influence of IT on $\mathrm{CO}_{2}$ emissions is statistically negligible in Russia and China. (Table 4). 
Table 4. Nation-wise FMOLS Test Results.

\begin{tabular}{|c|c|c|c|c|c|c|}
\hline Variable & $\operatorname{Ln}(Y)$ & $\operatorname{Ln}\left(Y^{2}\right)$ & $\operatorname{Ln}(\mathrm{EC})$ & $\operatorname{Ln}(E R)$ & $\operatorname{Ln}(\mathrm{IT})$ & Does EKC Hold? \\
\hline $\begin{array}{l}\text { South } \\
\text { Africa }\end{array}$ & $\begin{array}{c}50.836 * \\
(0.000)\end{array}$ & $\begin{array}{c}-2.903 * \\
0\end{array}$ & $\begin{array}{c}0.958 * \\
0\end{array}$ & $\begin{array}{c}-0.081 \\
* * *(0.064)\end{array}$ & $\begin{array}{c}-0.075 \text { * } \\
(0.000)\end{array}$ & Yes \\
\hline Russia & $\begin{array}{l}0.183 * \\
-0.006\end{array}$ & $\begin{array}{c}-0.022 \text { * } \\
0\end{array}$ & $\begin{array}{c}1.152 \text { * } \\
0\end{array}$ & $\begin{array}{c}-0.143 \text { * } \\
(0.000)\end{array}$ & $\begin{array}{l}0.081 \\
-0.1\end{array}$ & Yes \\
\hline India & $\begin{array}{c}1.391 * \\
0\end{array}$ & $\begin{array}{c}-0.214 \text { * } \\
0\end{array}$ & $\begin{array}{c}2.385 \text { * } \\
0\end{array}$ & $\begin{array}{c}-0.106 \text { * } \\
(0.000)\end{array}$ & $\begin{array}{c}0.327 \text { * } \\
0\end{array}$ & Yes \\
\hline China & $\begin{array}{c}0.3576^{* * *} \\
(0.061)\end{array}$ & $\begin{array}{c}-0.0291 \\
* * * \\
(0.079)\end{array}$ & $\begin{array}{l}1.0514 \text { * } \\
(0.000)\end{array}$ & $\begin{array}{c}-0.0747 \\
* *(0.021)\end{array}$ & $\begin{array}{c}-0.0717 \\
(0.196)\end{array}$ & Yes \\
\hline Brazil & $\begin{array}{l}0.3920 * \\
(0.001)\end{array}$ & $\begin{array}{c}-0.0383 * \\
(0.004)\end{array}$ & $\begin{array}{l}1.2192 \text { * } \\
(0.000)\end{array}$ & $\begin{array}{c}-0.0449 \text { * } \\
(0.000)\end{array}$ & $\begin{array}{c}0.0552 \text { * } \\
(0.000)\end{array}$ & Yes \\
\hline
\end{tabular}

Environmental restrictions in conjunction with economic growth can help to reverse the emissions trend in BRICS nations. Rising economies may use this approach to keep their Paris Agreement emission reduction pledges on track. BRICS countries dominate the world in technical innovation and information sharing. The findings are consistent with previous research on environmentally friendly technology and carbon pricing systems that are effective in reducing carbon emissions. Environmental rules reduce pollution in all BRICS nations since they have negative coefficients across the board. As a result, they have a favorable impact on reducing carbon emissions.

Consequently, environmental restrictions are crucial for relating emission reductions to technology advancements. Finally, the total environmental impact of trade is minimal. China and Russia's results are statistically insignificant. In South Africa, trade has a net negative impact on $\mathrm{CO}_{2}$ emissions; however, trade has a net positive impact in Brazil and India. In nations where trade has a positive impact on pollution, it is possible that clean technology is being transferred via trade.

\section{Conclusions}

This research considers the link between energy consumption, environmental policy measures, $\mathrm{CO}_{2}$ emissions and income in five BRICS nations from 1995 to 2018. In this research, the sample nations were initially evaluated as a full panel, and then nationspecific coefficients were computed. Environmental rules have a beneficial impact on climate change mitigation if they have a negative coefficient. The study also revealed that BRICS nations might reduce their carbon emissions by implementing environmental rules. According to the study's results, environmental restrictions are useful in lowering pollution and contribute to establishing EKC between pollution and per capita income.

The model includes energy consumption as a vital component, and it is a major source of pollution in the BRICS nations. Furthermore, international trade increases pollution in Brazil and India while lowering $\mathrm{CO}_{2}$ emissions in South Africa. In nations where trade has a positive impact on pollution, it is possible that clean technology is being transferred via trade. In addition, strong environmental rules may be to blame for limiting the importation and manufacturing of polluting imports and export-oriented items. In addition, commerce negatively impacts the environment in Brazil and India since it encourages the use of energy-intensive industries and technologies. Trade development in Brazil and India may allow for the employment of not-ecologically friendly machinery in the manufacture of commodities.

Considering the empirical facts connected to environmental regulations, environmental laws may effectively control environmental pollution and have a spillover impact on pollution. In summary, the obstacles that prohibit technology that is not environmentally friendly are the primary motivation for environment-related patents to have a beneficial impact on $\mathrm{CO}_{2}$ emissions [36]. Environmental rules aimed at promoting economic de- 
velopment successfully reduce pollution; however, they are insufficient to counteract the negative impact of energy use on pollution in the BRICS nations. However, in BRICS nations, energy and trade impacts greatly outweigh green innovation benefits and carbon pricing policy tools. Although economic growth alone will not be sufficient to minimize pollution, implementing necessary energy control measures will be beneficial. The outcome speaks volumes about policy methods for reducing pollution without jeopardizing access to energy.

Based on the study's estimated findings, various policy implications in terms of trade are offered. Because these economies are seeing fast development in overseas trade, nations with decreased pollution must enhance their environmental standards. Furthermore, Brazil and India must update their environmental standards for trade operations since commerce brings contaminated technology and commodities to these nations, limited by effective and strong environmental legislation. In BRICS nations, a major portion of energy produced is via fossil fuels, which have a detrimental impact on the environment because of their high carbon emissions. BRICS nations should enhance environmental command control rules to limit excessive energy use and improve energy efficiency.

The main difficulty faced in researching this topic was a lack of research on BRICS nations regarding environmental regulations and $\mathrm{CO}_{2}$ mitigation. Also, each nation has its own economic rules and culture, and, therefore, it was difficult to achieve the same measures for climate change. This study differs from previous research in terms of methodology, research variables and analytic time, which is another factor to consider. Several limitations were found that future research should take into account. The research might be expanded to consider the link between income, environmental legislation and carbon emissions for additional nations or groups. Globalization, corruption and other variables might be incorporated in the estimating model, emphasizing the necessity for environmental pollution reduction initiatives [52]. Future research may also use alternate pollution indicators or econometric methodologies to arrive at different conclusions.

Author Contributions: Conceptualization, M.S. and L.I.; methodology, M.S.; software, L.-I.C.; validation, M.S., and L.I.; formal analysis, L.I.; investigation, L.-I.C.; data curation, L.I.; writing-original draft preparation, M.S.; writing-review and editing, L.-I.C. and L.I.; supervision, L.-I.C.; project administration, M.S. All authors have read and agreed to the published version of the manuscript.

Funding: This research received no external funding.

Institutional Review Board Statement: Not applicable.

Informed Consent Statement: Not applicable.

Data Availability Statement: The data will be available upon request to the corresponding author.

Conflicts of Interest: The authors declare no conflict of interest.

\section{References}

1. Rehman, A.; Ma, H.; Ahmad, M.; Irfan, M.; Traore, O.; Chandio, A.A. Towards environmental Sustainability: Devolving the influence of carbon dioxide emission to population growth, climate change, Forestry, livestock and crops production in Pakistan. Ecol. Indic. 2021, 125, 107460. [CrossRef]

2. Zhang, B.; Wang, Z.; Wang, B. Energy production, economic growth and CO2 emission: Evidence from Pakistan. Nat. Hazards 2018, 90, 27-50.

3. Pachauri, R.K.; Allen, M.R.; Barros, V.R.; Broome, J.; Cramer, W.; Christ, R.; Church, J.A.; Clarke, L.; Dahe, Q.; Dasgupta, P.; et al. Climate Change 2014: Synthesis Report. Contribution of Working Groups I, II and III to the Fifth Assessment Report of the Intergovernmental Panel on Climate Change; IPCC: Geneva, Switzerland, 2014.

4. Murshed, M.; Alam, R.; Ansarin, A. The environmental Kuznets curve hypothesis for Bangladesh: The importance of natural gas, liquefied petroleum gas, and hydropower consumption. Environ. Sci. Pollut. Res. 2021, 28, 17208-17227. [CrossRef]

5. Wang, Z. Does biomass energy consumption help to control environmental pollution? Evidence from BRICS countries. Sci. Total Environ. 2019, 670, 1075-1083.

6. $\quad$ Rees, G.N.; Baldwin, D.S.; Watson, G.O.; Hall, K.C. Sulfide formation in freshwater sediments, by sulfate-reducing microorganisms with diverse tolerance to salt. Sci. Total Environ. 2010, 409, 134-139. [CrossRef] 
7. Wang, H.; Wei, W. Coordinating technological progress and environmental regulation in CO2 mitigation: The optimal levels for OECD countries \& emerging economies. Energy Econ. 2020, 87, 104510.

8. Wang, X.; Shao, Q. Non-linear effects of heterogeneous environmental regulations on green growth in G20 countries: Evidence from panel threshold regression. Sci. Total Environ. 2019, 660, 1346-1354. [CrossRef]

9. Van der Werf, E.; di Maria, C. Imperfect environmental policy and polluting emissions: The green paradox and beyond. Int. Rev. Environ. Resour. Econ. 2012, 6, 153-194. [CrossRef]

10. Khattak, S.I.; Ahmad, M.; Khan, Z.U.; Khan, A. Exploring the impact of innovation, renewable energy consumption, and income on CO2 emissions: New evidence from the BRICS economies. Environ. Sci. Pollut. Res. 2020, 27, 13866-13881. [CrossRef] [PubMed]

11. Chen, J.; Gao, M.; Cheng, S.; Hou, W.; Song, M.; Liu, X.; Liu, Y.; Shan, Y. County-level CO2 emissions and sequestration in China during 1997-2017. Sci. Data 2020, 7, 391. [CrossRef] [PubMed]

12. Kretschmer, B.; Hübler, M.; Nunnenkamp, P. Does foreign aid reduce energy and carbon intensities of developing economies? J. Int. Dev. 2013, 25, 67-91. [CrossRef]

13. Wang, Z.; Zhang, B.; Wang, B. The moderating role of corruption between economic growth and CO2 emissions: Evidence from BRICS economies. Energy 2018, 148, 506-513. [CrossRef]

14. Baloch, M.A.; Mahmood, N.; Zhang, J.W. Effect of natural resources, renewable energy and economic development on CO2 emissions in BRICS countries. Sci. Total Environ. 2019, 678, 632-638.

15. Ali, H.S.; Nathaniel, S.P.; Uzuner, G.; Bekun, F.V.; Sarkodie, S.A. Trivariate modelling of the nexus between electricity consumption, urbanization and economic growth in Nigeria: Fresh insights from Maki Cointegration and causality tests. Heliyon 2020, 6, e03400. [CrossRef]

16. Nathaniel, S.P.; Murshed, M.; Bassim, M. The nexus between economic growth, energy use, international trade and ecological footprints: The role of environmental regulations in N11 countries. Energy Ecol. Environ. 2021, 6, 496-512. [CrossRef]

17. Ulucak, R. How do environmental technologies affect green growth? Evidence from BRICS economies. Sci. Total Environ. 2020, 712,136504

18. Hao, Y.; Deng, Y.; Lu, Z.-N.; Chen, H. Is environmental regulation effective in China? Evidence from city-level panel data. J. Clean. Prod. 2018, 188, 966-976. [CrossRef]

19. Cheng, Z.; Li, L.; Liu, J. The emissions reduction effect and technical progress effect of environmental regulation policy tools. $J$. Clean. Prod. 2017, 149, 191-205. [CrossRef]

20. Wang, R.; Xiong, Y.; Xing, X.; Yang, R.; Li, J.; Wang, Y.; Cao, J.; Balkanski, Y.; Peñuelas, J.; Ciais, P.; et al. Daily CO2 emission reduction indicates the control of activities to contain COVID-19 in China. Innovation 2020, 1, 100062. [CrossRef] [PubMed]

21. Alam, M.M.; Murad, M.W. The impacts of economic growth, trade openness and technological progress on renewable energy use in organization for economic co-operation and development countries. Renew. Energy 2020, 145, 382-390. [CrossRef]

22. Shah, S.G.M.; Sarfraz, M.; Ivascu, L. Assessing the interrelationship corporate environmental responsibility, innovative strategies, cognitive and hierarchical CEO: A stakeholder theory perspective. Corp. Soc. Responsib. Environ. Manag. 2021, 28, 457-473. [CrossRef]

23. Chen, H.; Hao, Y.; Li, J.; Song, X. The impact of environmental regulation, shadow economy, and corruption on environmental quality: Theory and empirical evidence from China. J. Clean. Prod. 2018, 195, 200-214. [CrossRef]

24. Vickers, N.J. Animal communication: When I'm calling you, will you answer too? Curr. Biol. 2017, 27, R713-R715. [CrossRef] [PubMed]

25. Jiang, Y.; Zhou, Z.; Liu, C. Does economic policy uncertainty matter for carbon emission? Evidence from US sector level data Environ. Sci. Pollut. Res. 2019, 26, 24380-24394. [CrossRef] [PubMed]

26. Hashmi, R.; Alam, K. Dynamic relationship among environmental regulation, innovation, CO2 emissions, population, and economic growth in OECD countries: A panel investigation. J. Clean. Prod. 2019, 231, 1100-1109. [CrossRef]

27. Qingquan, J.; Khattak, S.I.; Ahmad, M.; Ping, L. A new approach to environmental sustainability: Assessing the impact of monetary policy on CO2 emissions in Asian economies. Sustain. Dev. 2020, 28, 1331-1346. [CrossRef]

28. Xie, Q.; Wang, X.; Cong, X. How does foreign direct investment affect $\mathrm{CO} 2$ emissions in emerging countries? New findings from a nonlinear panel analysis. J. Clean. Prod. 2020, 249, 119422. [CrossRef]

29. Shehzad, K.; Xiaoxing, L.; Sarfraz, M.; Zulfiqar, M. Signifying the imperative nexus between climate change and information and communication technology development: A case from Pakistan. Environ. Sci. Pollut. Res. 2020, 27, 30502-30517. [CrossRef]

30. Ouyang, X.; Shao, Q.; Zhu, X.; He, Q.; Xiang, C.; Wei, G. Environmental regulation, economic growth and air pollution: Panel threshold analysis for OECD countries. Sci. Total Environ. 2019, 657, 234-241. [CrossRef]

31. Albulescu, C.T.; Artene, A.E.; Luminosu, C.T.; Tămășilă, M. CO2 emissions, renewable energy, and environmental regulations in the EU countries. Environ. Sci. Pollut. Res. 2020, 27, 33615-33635. [CrossRef] [PubMed]

32. Sarfraz, M.; Shehzad, K.; Farid, A. Gauging the air quality of New York: A non-linear Nexus between COVID-19 and nitrogen dioxide emission. Air Qual. Atmos. Health 2020, 13, 1135-1145. [CrossRef] [PubMed]

33. Shen, J.; Wei, Y.D.; Yang, Z. The impact of environmental regulations on the location of pollution-intensive industries in China. $J$. Clean. Prod. 2017, 148, 785-794. [CrossRef]

34. Leme, R.D.; Nunes, A.O.; Silva, D.A.L. Creating value with less impact: Lean, green and eco-efficiency in a metalworking industry towards a cleaner production. J. Clean. Prod. 2018, 196, 517-534. [CrossRef] 
35. Yusof, N.; Abidin, N.Z.; Zailani, S.H.M.; Govindan, K.; Iranmanesh, M. Linking the environmental practice of construction firms and the environmental behaviour of practitioners in construction projects. J. Clean. Prod. 2016, 121, 64-71. [CrossRef]

36. Zhang, K.; Xu, D.; Li, S. The impact of environmental regulation on environmental pollution in China: An empirical study based on the synergistic effect of industrial agglomeration. Environ. Sci. Pollut. Res. 2019, 26, 25775-25788. [CrossRef]

37. Ajaz, A.; Shenbei, Z.; Sarfraz, M. Delineating the influence of boardroom gender diversity on corporate social responsibility, financial performance, and reputation. Logforum 2020, 16, 61-74.

38. Wang, M.; Feng, C. How will the greening policy contribute to China's greenhouse gas emission mitigation? A non-parametric forecast. Environ. Res. 2021, 195, 110779. [CrossRef]

39. Wang, M.; Feng, C. The win-win ability of environmental protection and economic development during China's transition. Technol. Forecast. Soc. Chang. 2021, 166, 120617. [CrossRef]

40. Sarkodie, S.A.; Strezov, V.; Weldekidan, H.; Asamoah, E.F.; Owusu, P.A.; Doyi, I.N.Y. Environmental sustainability assessment using dynamic autoregressive-distributed lag simulations-Nexus between greenhouse gas emissions, biomass energy, food and economic growth. Sci. Total Environ. 2019, 668, 318-332. [CrossRef]

41. Alola, A.A.; Bekun, F.V.; Sarkodie, S.A. Dynamic impact of trade policy, economic growth, fertility rate, renewable and nonrenewable energy consumption on ecological footprint in Europe. Sci. Total Environ. 2019, 685, 702-709. [CrossRef]

42. Asumadu-Sarkodie, S.; Yadav, P. Achieving a cleaner environment via the environmental Kuznets curve hypothesis: Determinants of electricity access and pollution in India. Clean Technol. Environ. Policy 2019, 21, 1883-1889. [CrossRef]

43. Cheng, S.-C.; Wu, T.; Lee, K.-C.; Chang, T. Flexible Fourier unit root test of unemployment for PIIGS countries. Econ. Model. 2014, 36, 142-148. [CrossRef]

44. Semančíková, J. Trade, trade openness and macroeconomic performance. Procedia-Soc. Behav. Sci. 2016, 220, 407-416. [CrossRef]

45. Mahmood, N.; Wang, Z.; Yasmin, N.; Manzoor, W.; Rahman, A.U. How to bend down the environmental Kuznets curve: The significance of biomass energy. Environ. Sci. Pollut. Res. 2019, 26, 21598-21608. [CrossRef] [PubMed]

46. Mensah, I.A.; Sun, M.; Gao, C.; Omari-Sasu, A.Y.; Zhu, D.; Ampimah, B.C.; Quarcoo, A. Analysis on the nexus of economic growth, fossil fuel energy consumption, CO2 emissions and oil price in Africa based on a PMG panel ARDL approach. J. Clean. Prod. 2019, 228, 161-174. [CrossRef]

47. Zhang, J.; Hassan, S.T.; Iqbal, K. Toward achieving environmental sustainability target in Organization for Economic Cooperation and Development countries: The role of real income, research and development, and transport infrastructure. Sustain. Dev. 2020, $28,83-90$.

48. Danish; Wang, Z. Investigation of the ecological footprint's driving factors: What we learn from the experience of emerging economies. Sustain. Cities Soc. 2019, 49, 101626. [CrossRef]

49. Atasoy, B.S. Testing the environmental Kuznets curve hypothesis across the US: Evidence from panel mean group estimators. Renew. Sustain. Energy Rev. 2017, 77, 731-747. [CrossRef]

50. Kapetanios, G.; Pesaran, M.H. Alternative Approaches to Estimation and Inference in Large Multifactor Panels: Small Sample Results with an Application to Modelling of Asset Returns; CESifo Working Paper; Center for Economic Studies and ifo Institute (CESifo): Munich, Germany, 2005.

51. El Anshasy, A.A.; Katsaiti, M.-S. Energy intensity and the energy mix: What works for the environment? J. Environ. Manag. 2014, 136, 85-93. [CrossRef]

52. Hassan, S.T.; Khan, S.U.-D.; Xia, E.; Fatima, H. Role of institutions in correcting environmental pollution: An empirical investigation. Sustain. Cities Soc. 2020, 53, 101901. [CrossRef] 